\title{
NO ES MI CULPA, FUE MI CEREBRO. ¿ES ESTA UNA AFIRMACIÓN VÁLIDA PARA APLICAR LA INIMPUTABILIDAD A INDIVIDUOS CON TRASTORNOS DE LA PERSONALIDAD Y PSICÓPATAS?*
}

Custodia Jiménez Martínez***

\begin{abstract}
Resumen: En este artículo se aborda el estudio de la responsabilidad jurídica e inimputabilidad de los delitos cometidos por individuos con trastornos de la personalidad y psicópatas, así como los supuestos que se han desarrollado en más de una treintena de años en las neurociencias para refutar un concepto fundamental del Derecho Penal moderno, esto es, el pensamiento de que en el hombre existe libertad para actuar y decidir su conducta ilícita. Bajo el esquema de la neurociencia no existiría la aludida libertad, puesto que esta sería un espejismo ya que el cerebro ordenaría previamente nuestra conducta.
\end{abstract}

* El presente trabajo se inscribe en los proyectos de investigación DER2013-47511-R y DER201676715-R (Ministerio de Economía y Competitividad de España-Mineco-), de los que el Investigador Principal es el Prof. Dr. Miguel Díaz y García Conlledo y de cuyo equipo de trabajo formo parte.

** Doctora en Derecho Penal UNED. Abogada Penalista en el Ilustre Colegio de Abogados de Madrid. Colaboradora del Departamento de Derecho Penal de la Universidad de León. Barcelona, España. Correo-e: custodiajimenez@telefonica.net Fecha de recepción: 26 de octubre de 2016. Fecha de modificación: 15 de noviembre de 2016. Fecha de aceptación: 24 de febrero de 2017. Para citar el artículo: JimÉnEz MARTínEZ, CUSTODIA (2016). "No es mi culpa, fue mi cerebro. ¿Es esta una afirmación válida para aplicar la inimputabilidad a individuos con trastornos de la personalidad y psicópatas?”, en Revista Derecho Penal y Criminología, Vol.37, n. ${ }^{\circ} 103$, julio-diciembre de 2016, Bogotá: Universidad Externado de Colombia, pp. 81-107, DOI: https://doi.org/10.18601/01210483.v37n103.05 
Palabras clave: responsabilidad jurídica, trastornos de personalidad, psicópatas, libertad para actuar, neurociencia.

\title{
"IT'S NOT MY FAULT, IT WAS MY BRAIN". COULD SUCH A STATEMENT LEAD TO AN EXCUSE FOR INDIVIDUALS WITH PERSONALITY DISORDERS AND PSYCHOPATHS?
}

\begin{abstract}
In this paper we study both the criminal responsibility and the mental state as excuse for indivisuals with personality disorders and psychopaths, as well as the arguments offered by the neuroscience to deny a basic, central, main, nuclear stone of our modern criminal law, the idea of a free will. According to that idea, the human being is free to choose between the right and wrong (unlawful) behavior. For neuroscience we don't have such a freedom that would be merely an illusion, a mirage. Our brain would have decided and ordered formerly our behavior.
\end{abstract}

Keywords: legal responsability, personality disorders, psychopaths, freedom to act, neuroscience, criminal law, insanity plea.

\section{CONFLUENCIA DE DERECHO Y NEUROCIENCIA}

El derecho tiene por objeto la regulación de las relaciones entre las personas, mediante el dictado de supuestos hipotéticos, generales y abstractos de conducta descritos en la norma, con el propósito de la protección de un valor justo y conveniente para la sociedad en la que tiene validez.

Por otra parte, se atribuye al cerebro la facultad de constituir la causa o razón de todo comportamiento. Entonces no resulta difícil entender la necesaria confluencia y el sentido inevitable de convergencia entre el derecho y la neurociencia.

Como explica Garzón Valdez, a partir de los experimentos neurológicos realizados en los años ochenta del siglo pasado, por el profesor Dr. Benjamín Libet, del Centro de Neurociencia de la Universidad de California at Davis, "la vieja discusión acerca de hasta qué punto somos libres autores de nuestro comportamiento ha despertado renovado interés no solo entre científicos del cerebro y filósofos puros sino también entre filósofos del derecho y penalistas". Y concluye su pensamiento: "No existe un correlato neuronal de la conciencia. Los argumentos que se aducen ya no son únicamente filosóficos sino que pretenden sustentación empírico científico"1.

1 Garzón Valdez, E. (enero, 2011). "Cerebro y responsabilidad penal", en Seminario de Filosofía del Derecho. Barcelona: Universidad Pompeu Fabra. 
El problema no radica precisamente en la aceptación generalizada de esta premisa, donde todos parecen estar de alguna manera de acuerdo, ya que sin la presencia del cerebro no se concibe la posibilidad de manifestación de voluntad alguna, a lo que debe agregarse otra conclusión igualmente válida, en el sentido de que los avances de las investigaciones y certezas científicas acerca del cerebro que se adquieran en el futuro tendrán inevitablemente una mayor repercusión sobre las ciencias normativas.

La gran diferencia entre las diversas posiciones radica en el mayor o menor grado de determinabilidad o necesidad que se le asigna a este fenómeno, el que para unos será inevitablemente universal y absorbente y para otros, por el contrario, solo una cuestión importante, pero sin llegar a asignarle un grado de rigidez semejante en lo que respecta a las conclusiones específicas.

La cuestión pasa por la solución de fórmulas que sobre la base del respeto y reconocimiento de ambas realidades, y sin que una lleve a la desaparición de la otra, sea factible encontrar un punto de reunión, equilibrio o confluencia entre ellas que permita la supervivencia de ambas, cuestión donde se libra actualmente el debate más profundo de la "neurociencia y el derecho".

Quizá, para ser más exactos, habría que remontarse al campo de la ética y reflexionar en torno a conceptos como "conciencia" o "libre albedrío"2, es decir, la posibilidad de mantener los márgenes de libertad suficiente como para que una persona pueda ser responsable de sus propios actos, situación que desaparece en el caso de llegar a conclusiones capaces de sostener que el hombre actúa condicionado o influenciado absolutamente por los mandatos e imperativos de su cerebro, de forma tal que el azar de la imposición determinista hace desaparecer las diversas opciones posibles.

Lo mismo sucede con la explicación relacionada con la toma de "conocimiento de sí mismo", en el sentido de que si esta existe, lo es solo por obra y decisiones del cerebro, o si por el contrario, resulta factible encontrar otros elementos colaboradores, tales como los que provienen de circunstancias culturales, ambientales o personales, capaces de influir conjuntamente con los mandatos encefálicos en relación a la estricta conciencia del "yo personal".

2 Capó, M.; Nadal, M.; Ramos, C.; Fernández, A.; Cela Conde, C. J. (2006). "Neuroética, derecho y neurociencia" en Ludus Vitalis, vol. XIV, n. ${ }^{\circ} 25,2006$, p. 163 y ss. Describen con mucha precisión las vinculaciones que median en el uso de las técnicas de imaginería cerebral para investigar los correlatos neuronales de ciertos comportamientos en la toma de decisiones morales, en el sentido de brindar explicaciones sobre dimensiones clásicas de la personalidad, tales como la extroversión o la neurosis. Por otra parte, aluden también a la vinculación de estas disciplinas con aspectos posibles de interés de la filosofía tradicional, que incluyen: “i) la ética de la práctica neurocientífica como una extensión de la bioética tradicional; ii) la preocupación por la mejora o potenciación de las capacidades cognitivas (cognitive enhancement) y finalmente iii) los posibles usos jurídicos de los avances neurocientíficos, ya sea como medio de prueba o mediante la modificación, gracias a estos avances, de ciertas concepciones jurídicas". 
Algunos autores, con la finalidad de formular el desarrollo lógico de esta cuestión, se preguntan si es posible establecer una diferenciación entre mente y cerebro ${ }^{3}$, o siguiendo este razonamiento, si el órgano anatómico conforma solo una parte ubicada dentro de un todo que integran los elementos gravitantes de la conducta de una persona, aunque de ninguna manera la comprenden o subsumen dentro de una visión exclusivista y absoluta.

La respuesta a este interrogante que preocupara a filósofos y juristas desde hace muchísimos años, se advierte claramente en el pensamiento de Descartes cuando describía la mente "como una misteriosa sustancia inmaterial independiente, pero a

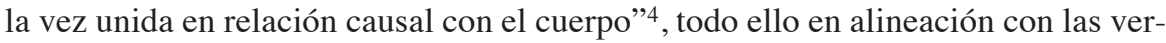
siones más antiguas influidas -seguramente- por posturas dogmáticas o religiosas que consideraban las diferencias existentes entre mente y alma como si se tratasen de dos componentes autónomos, uno material y el otro espiritual, que deben ser considerados en forma independiente para el hallazgo de una descripción completa y detallada de la conducta humana.

Parece suficientemente claro que las reflexiones precedentes nos transportan nada menos que al concepto mismo de libertad o libre albedrío, presupuestos ontológicos únicosy exclusivos para atribuir a la persona un juicio de reproche moral o atribución de responsabilidad legal.

Solo quien se encuentra bajo el "completo dominio" o "imperio de sî", con aptitud para discernir entre diversas alternativas y elegir en consecuencia, configuraría el supuesto supeditado a imponer a esa conducta una sanción de responsabilidad, tanto de orden resarcitivo como punitivo.

Para construir una "teoría de la responsabilidad" debe buscarse fundamento sobre el presupuesto ineludible de la libertad o libre albedrío y completo discernimiento del autor respecto de los hechos o actos que van a ser objeto de juicio o valoración judicial.

3 CAPÓ, M., et. al., Op. Cit., pp. 163 y ss.

4 PARdo, M. S. y PATterson, D. (abril, 2011). "Fundamentos filosóficos del derecho y la neurociencia" en InDret, Barcelona. Disponible en http://www.indret.com/pdf/819.pdf. En el abstract de este magnífico y erudito trabajo se afirma: "Según una amplia variedad de académicos, científicos y responsables políticos, la neurociencia acabará por transformar el derecho. Muchos neurojuristas -valedores del poder de la Neurociencia sobre el derecho- proceden a partir de premisas problemáticas acerca de la relación existente entre mente y cerebro. En este artículo los profesores PARDO Y PATTERSON sostienen que las explicaciones neurolegalistas de la naturaleza de la mente no son plausibles y que sus conclusiones han sido artificiosamente infladas. Por ende, las pretensiones neurolegalistas acerca del poder de la neurociencia sobre el derecho no pueden ser sostenidas. Los autores tratan una amplia selección de ejemplos, entre los que se incluyen la detección de mentiras, los fundamentos del Derecho Penal, la toma de decisiones económicas, la toma de decisiones morales y las teorías generales de la Ciencia y del Derecho". 
Acorde con las consideraciones precedentes, y en particular en lo referente a la temática de las relaciones que vinculan la "mente" y el "cerebro", se perfilan dos grandes corrientes, a saber:

Por un lado, aparecen las posiciones "unitarias", "materialistas" o "deterministas", que asignan al cerebro una participación absoluta y excluyente de todo otro factor o consideración como causa eficiente o atribución causal de la conducta humana.

Contrapuesta con la posición anterior, se establecen otras teorías que llamaremos dualistas las que, sin dejar de reconocer la importancia de las tareas que cumple el "cerebro",-observación que, por otra parte, parece obvia- no se le asignan funciones absolutas, admitiendo por el contrario, una diversidad de factores y habilidades que a la postre inciden o contribuyen sobre la eficacia y efectos de toda manifestación de voluntad.

La concepción "unitaria", "materialista" o "determinista" 5 concibe a la mente como reducida o absorbida totalmente por el cerebro, de forma tal que todos los negocios, actos $\mathrm{u}$ operaciones posibles terminan siendo explicados a través de las funciones específicas de este órgano en particular, de forma tal que no queda nada fuera de este contexto y premisa lógica fundamental.

Las distintas observaciones que se asocian normalmente con la mente únicamente encuentran una razón válida a través del cerebro, atribuyéndole no solo el discurrir o el pensar (vida discursiva), sino también las creencias, emociones, percepciones y sentimientos (vida afectiva) ${ }^{6}$.

Dicho de otra manera, todo lo que se ve o puede llegar a ser objeto de tratamiento por el derecho resulta siempre de una exteriorización o manifestación cerebral, de tal que nada puede encontrarse fuera de su protagonismo y centralidad con respecto a la vida de relación entre las personas.

Desde esta perspectiva se simplifica la sinergia del comportamiento de las personas a través de afirmaciones categóricas y terminantes como "tú eres el cerebro" y por

5 Michael S. Pardo, Dennis Patterson, Op. Cit., nota 9.

6 GARZÓn VALDEZ, E. Op. Cit., nota n. ${ }^{\circ}$ 7,p. 27, que textualmente expresa: “Todas (las) manifestaciones del comportamiento (...) pueden ser (....) remitidas a procesos neuronales en el sentido de una relación causal (...) el cerebro humano casi no se diferencia en nada del de los animales; (...) Dado que con respecto al cerebro de los animales no tenemos ningún motivo para dudar que todo el comportamiento se basa en funciones del cerebro y, por lo tanto, está sometido a las leyes deterministas de procesos físico-químicos, la tesis del condicionamiento material del comportamiento debe valer también para las personas. (...) Las células nerviosas de un caracol funcionan según los mismos principios que las células nerviosas de la corteza cerebral humana. (...) Esto nos conduce a la muy desagradable conclusión de que todo lo que hace que seamos lo que somos y nos diferencia de los animales y, por lo tanto, todo lo que posibilita nuestra evolución cultural se basa en un aumento cuantitativo de una determinada estructura cerebral". 
la identificación de la base neuronal del comportamiento, nos proyectan obligatoriamente sobre cuestiones o conceptos como el libre albedrío, la libertad y lógicamente - porque no podría ser de otra manera-, al contenido y alcance de todo juicio de imputación que haga el derecho en torno a la construcción de una "teoría de la responsabilidad".

De esta manera el núcleo al interrogante que tiende a arrojar luz acerca de una determinada exteriorización de la de voluntad concluye con la necesidad de otra investigación inevitable: ¿era o fue él o su cerebro?

\section{MI CEREBRO ME HIZO HACER ESO}

Unas de las afirmaciones sólidas en la literatura sobre el cerebro es que nosotros somos nuestro cerebro o, al menos, cuando nuestro cerebro sufre alguna alteración hay registros de "alteración en nuestro yo"7. Esto no ocurre, por ejemplo, cuando sufrimos alguna lesión en nuestro brazo o pierna o, inclusive, en la espalda. Pero cuando partes de nuestra cabeza quedan afectadas perdemos la capacidad de hablar, de expresar emociones, de ver, en fin, de realizar actividades comunes.

\subsection{State of Utah v. Tomás R. Herrera}

Pocos minutos después de la medianoche del día 6 de junio de 1991, Tomás R. Herrera entró en la casa de su exnovia Claudia Martínez ${ }^{8}$, se dirigió a su habitación y, después de estrangularla, le disparó en la cabeza dos veces, provocándole la muerte. Al salir de la habitación, Herrera se encontró con la madre de Claudia, Rosa, en

7 Uno de los casos frecuentemente referidos para demostrar esta relación ha sido ampliamente divulgado en el año 2002. Un hombre de cuarenta años de edad, profesor de escuela, comienza a visitar sitios web de pornografía infantil. Amigos y familiares se extrañaron por su comportamiento y, después de un examen y una investigación al respecto sobre los fuertes dolores de cabeza que sentía, fue detectado por el fMRI un tumor casi del tamaño de un pequeño huevo en su lóbulo frontal. Luego de una operación que retiró el tumor, sus impulsos de visitar los sitios web de pornografía infantil cesaron. Meses después vuelve a sentir impulsos pedófilos y fuertes dolores de cabeza. Los exámenes realizados identifican que un nuevo tumor había crecido en el lugar del antiguo. Esta fue la primera vez que relacionaron los problemas en el cerebro con el comportamiento pedófilo. BURNS, JEFFREY M. y SwerdLOW, RuSSELl H. (2003). "Right orbitofrontal tumor with pedophilia symptom and constructional apraxia sign", en "Archives of Neurology", 60, p. 438.; TOST, HeIKE; VolLmERT, Christian; Brassen, Stefanie; Schmitt, Andrea; Dressing, Harald; Braus, Dieter F. (2004) "Pedophilia: Neuropsychological evidence encouraging a brain network perspective", en Medical Hypothesis, 63, 3, p. 530.; Schiffer, Boris; Peschel, Thomas; Gizewski, Thomas; Forsting, Elke; Leygraf, Michael; Schedlowski, Norbert; Krueger, Manfred; Tillmann, Kruger H. C. (2007). "Structural brain abnormalities in the frontostrital system and cerebellum in pedophilia", en Journal of Psychiatric Research, 41, 9, p. 755.

8 Supreme Court of State of Utah, Plaintiff and Appellee v. Tomas R. Herrera, Defendant and Appellant., n. ${ }^{\circ} 980145$, FILED, June 29, 1999. 
la sala. Rosa, notando lo ocurrido, intentó escapar yendo a la habitación de su hijo Reuben. Herrera la persiguió y, una vez dentro de la habitación de Reuben, le disparó causándole lesiones no fatales. Se dirigió también a Reuben y le disparó errando el blanco. Lo intentó algunas veces más, pero se quedó sin munición.

Avisada por los vecinos, llegó la policía y detuvo a Herrera, a quien le leyeron sus derechos. Herrera le contó a la policía que estaba conduciendo su coche cerca de la residencia de Claudia cuando perdió el control sobre sí mismo y decidió matarla; admitió haberlo hecho y haber atentado contra la vida de Rosa y Reuben. El Estado de Utah ejerció una acción penal contra Herrera, acusándolo de homicidio y de doble atentado a la vida.

El Dr. Breck Lebegue, especialista forense, fue llamado para examinar el estado mental de Herrera en el momento de los disparos. Basándose en el examen realizado, el Dr. Breck Lebegue concluyó que Herrera sufría del Síndrome de Capgrass ${ }^{9}$. Conforme a su opinión, cuando Herrera mató a Claudia "él creía que estaba matando a alguien que no era un ser humano"10. Según Herrera, la mafia capturó a su exnovia y puso en su lugar a una impostora.

Pero, conforme a la opinión del Dr. Breck cuando Herrera atentó contra la vida de Rosa y Reuben, él sabía que estaba atentando contra la vida de seres humanos.

Herrera fue condenado por el atentado a la vida de Rosa y Reuben y considerado mentalmente enfermo en cuanto a la acusación de matar a Claudia.

La defensa de Herrera argumentó para el recurso que teniendo en cuenta que se ha considerado enfermo a Herrera y, por lo tanto, no pasible de encarcelamiento por la muerte de Claudia, se debería utilizar el mismo argumento para los atentados contra la vida de Rosa y Reuben, considerando que forman parte del mismo episodio de crisis. Este argumento fue rechazado por el juez dado que, según la opinión del especialista, distinguir víctimas no es incompatible con el síndrome, de modo que puede sufrir locura en cuanto a determinadas personas y no en cuanto a otras.

9 El Síndrome de Capgrass fue descrito por primera vez por Joseph Capgrass, psiquiatra francés, en 1923, al estudiar a una paciente que continuamente sostenía que "dobles" habían tomado el lugar de su marido y otros conocidos. Una característica de este síndrome es el no reconocimiento de personas, lugares u objetos como "reales", pudiéndose manifestar de forma leve o muy grave. En casos graves las personas son consideradas como "impostoras", "alienígenas" o "robots". Este síndrome se relaciona con sucesos de lesiones cerebrales comunes en accidentes que afectan a la cabeza. ELLIS, HADYN D. y Lewis, Michael B. (2001). “Capgrass delusion: A window on face recognition”, en Trends in Cognitive Sciences, 5, 4, pp. 113-121.

10 Supreme Court of State of Utah, Plaintiff and Appellee v. Tomas R. Herrera, Defendant and Appellant., n. ${ }^{\circ}$ 980145, FILED June 29, 1999. 


\subsection{People State New York v. Herbert Weinstein}

"Yo no hice eso, fue mi cerebro" es la síntesis de una defensa paradójica, según la cual los defectos en el cerebro -demostrados por fMRI (Functional Magnetic Resonance Imaging o Resonancias Magnéticas Funcionales, en español)- sugieren el origen del acto violento ${ }^{11}$.

En lo referente al caso People State New York v. Herbert Weinstein ${ }^{12}$, de 1992, el abogado de sesenta y cinco años de edad Herbert Weinstein fue acusado de asesinato. Conforme a la acusación, Weinstein mató a su mujer, Bárbara, por estrangulamiento, y para encubrir el crimen fingió un suicidio, arrojándola desde el piso doce del apartamento en el que vivían en Manhattan.

Con el objetivo de apoyar la defensa, se anexaron los escáneres del cerebro de Weinstein (PET -Positron Emission Tomography-). El propósito de las imágenes era el de posibilitar que neurólogos y psiquiatras estudiasen las funciones metabólicas del cerebro de Weinstein en sus varias regiones. La defensa de Weinstein afirmó que él tenía lesiones en el lóbulo frontal del cerebro causadas por un quiste aracnoideo, de modo que, según los especialistas, su presencia se encontraría exactamente en la parte del cerebro que controla todo el pensamiento y el comportamiento voluntario ${ }^{13}$.

La acusación argumentó que la prueba del quiste aracnoideo no debería ser admitida en el proceso. Conforme a la decisión del juez Richard Carruthers, bajo la regla de la admisibilidad de la prueba, podían mostrarse las imágenes del cerebro, pero no sería posible decirles a los jurados que estas estarían indiscutiblemente relacionadas con la violencia. Fundamentó su decisión invocando precedentes de People

11 Se registra el caso de Brian Dugan como el primero en utilizar esa técnica para efectos judiciales (antes de eso otra técnica ya había sido empleada para analizar la condición cerebral de John Hinckley Jr., cuando este atentó contra la vida del Presidente de los EEUU Ronald Reagan para llamar la atención de la actriz Jodie Foster). Dugan fue sometido a un exhaustivo examen de resonancia magnética cerebral (fMRI) por más de 90 minutos, bajo la supervisión de Kent Kiehl, neurocientífico de la Universidad de Nuevo México. El propósito del examen era comprender cómo funcionaba el cerebro de Dugan y si era posible usar esos datos en el juicio. Dugan había sido condenado por estupro y asesinato de tres personas. Jeanine Nicarico, de Illinois, fue su primera víctima. En el año 1983, Dugan la llevó a su coche y la violó en el asiento de atrás y la golpeó hasta matarla. En el año 1984, mató a su segunda víctima, una enfermera. El crimen fue parecido al primero. Dugan la violó, la mató y abandonó su cuerpo inerte poco después. El tercer crimen tuvo como víctima a una niña de siete años de edad que estaba andando en bicicleta. Dugan la violó, mató y tiró su cuerpo a la basura. ViRginia HugHES, Head case, in Nature, 464, 18, 2010, pp. 340-342.

12 Supreme Court of New York, People State New York v. Herbert Weinstein, October 8 (1992).

13 El lóbulo frontal en los seres humanos es responsable del control de las llamadas funciones ejecutivas del cerebro. La habilidad de actuar racionalmente y de planear constituyen sus más importantes funciones. El lóbulo frontal, en otras palabras, es el área responsable del poder cognitivo humano. Según las evidencias disponibles, los daños al lóbulo frontal pueden generar efectos adversos en la capacidad de la persona de actuar racionalmente. 
v. Stone ${ }^{14}$ y People v. Sugdets ${ }^{15}$. El especialista forense, Dr. Daniel Martell, por lo tanto, solo declaró que la tecnología era nueva y prometedora en el análisis del comportamiento humano.

Conforme a lo expuesto por el especialista Daniel Martell, "las debilidades cognitivas son señales de disfunción en el lóbulo frontal”. Según él, "los daños en el lóbulo frontal pueden presentar erosiones en la capacidad de juicio de la persona. Este es el aspecto generalmente aceptado como válido en el campo de la psiquiatría, psicología y neurología"16.

Esas lesiones fueron provocadas por un quiste aracnoideo. Los quistes aracnoideos son sacos de líquido localizados entre las membranas que cubren el cerebro que forman una red parecida a una tela de araña, como el propio nombre sugiere. Los quistes aracnoideos son de naturaleza congénita, es decir, ya están presentes en el nacimiento.

Once días después del cierre de las consideraciones, el acusado fue condenado con una reducción de pena. A partir de este caso, la pericia de neurocientíficos es frecuente en otros procesos, sobre todo norteamericanos.

\subsection{Roper v. Simmons}

Los niños pueden saber lo que es correcto y lo que no. Hay estudios que señalan que los niños de hasta seis años de edad saben que matar es incorrecto. Entretanto, dada la inmadurez de sus cerebros, los niños y los adolescentes tienen menor capacidad para controlar sus impulsos, para usar la razón como guía de comportamiento o, inclusive, para reflexionar con respecto a las posibles implicaciones de sus actos. Esta fue la conclusión del caso Roper v. Simmons, según la cual condenar niños y adolescentes a muerte viola la Constitución Norteamericana.

Con apenas diecisiete años de edad, Christopher Simmons planeó el asesinato de Shirley Crook conjuntamente con dos amigos: Charler Benjamin y John Tessmer. El plan era cometer un asalto y matar a la víctima, arrojándola desde un puente. En medio de la noche los tres se encontraron, pero John Tessmer desistió en el último instante. Simmons y Benjamin entraron en la casa de la víctima, robaron y, cubriendo la cabeza y atando las manos de Shirley, la arrojaron desde el puente.

1435 N.Y. 2 d 69 (1974). https://casetext.com/case/people-v-stone-80

1535 N.Y.2d 453 (1974). http://www.leagle.com/decision/197448835NY2d453_1426.xml/PEOPLE\%20 v.\%20SUGDEN

1635 N.Y. 2d 453 (1974). 
En el juicio las pruebas en contra de Simmons fueron consideradas consistentes, incluso se contó con su confesión, se realizó una reconstitución del crimen con la presencia del propio Simmons que fue grabada en video para ser mostrada al Jurado. Después de deliberar, el Jurado regresó con el veredicto de pena de muerte, incluso habiendo tenido en cuenta las circunstancias atenuantes del caso. Simmons a partir de entonces aguardaría la fecha para su ejecución.

Sin embargo, en el año 2002, la Suprema Corte decidió el caso Atkins v. Virginia ${ }^{17}$, según el cual las personas con problemas mentales no podrían ser condenadas a la pena de muerte. La defensa de Simmons, así, presentó una solicitud para que se considere el caso de adolescentes con el fin de extender la imposibilidad de la pena de muerte ${ }^{18}$.

El 13 de octubre de 2004 la Suprema Corte retomó el caso Simmons y, aceptando la posición de especialistas, estableció, en su decisión, tres razones para impedir que jóvenes criminales sean incluidos entre los criminales pasibles de pena de muerte. En primer lugar, "[la] falta de madurez y un sentido de responsabilidad subdesarrollado se encuentra con más frecuencia en jóvenes que en adultos; y son más comprensibles entre los jóvenes. Estas cualidades muchas veces tienen como resultado acciones y decisiones impetuosas o irreflexivas"19.

La segunda área de diferencia es que los jóvenes son más vulnerables o susceptibles a influencias negativas y presiones externas, incluyendo la presión de los $\operatorname{colegas}^{20}$.

La juventud es más que un hecho cronológico. Es un tiempo y una condición de vida, cuando una persona puede ser más susceptible a la influencia y a los daños psicológicos (...). Esto se explica en parte por la circunstancia predominante de que los jóvenes tienen menos control, o menos experiencia con el control, sobre su propio ambiente ${ }^{21}$.

La tercera gran diferencia es que el carácter de un joven no está tan bien formado como el de un adulto. Los trazos de personalidad de los jóvenes son más transitorios,

17 Roperv.Simmons, 543 U.S. 551 (2005). Disponible en https://www.law.cornell.edu/supct/html/03-633. ZS.html

18 US Supreme Court, n..$^{\circ}$ 03-633, Donald P. Roper v. Christopher Simmons, Brief for the American Psychological Association, and the Missouri Psychological Association as Amici Curiae, pp. 1-30. Disponible en http://www.apa.org/about/offices/ogc/amicus/roper.pdf

19 US Supreme Court, n. ${ }^{\circ}$ 03-633, Donald P. Roper v. Christopher Simmons, Brief for the American Psychological Association, and the Missouri Psychological Association as Amici Curiae, pp. 1-30. Disponible en http://www.apa.org/about/offices/ogc/amicus/roper.pdf

20 Ibidem.

21 Vid. Steinberg, Laurence y Scott, Elizabeth (2003). "Less Guilty by Reason of Adolescence: Developmental Immaturity, Diminished Responsibility, and the Juvenile Death Penalty, en Am. Psychologist, Vol. 58, n. ${ }^{\circ}$ 12, p. 1009. 
menos fijos. Esas diferencias hacen dudar de las conclusiones de que un joven se ajuste entre los peores criminales; “(...) su conducta irresponsable no es tan moralmente reprobable como la de un adulto”, decidió la Corte. Su propia vulnerabilidad y comparable falta de control sobre su entorno inmediato significa que “(...) los jóvenes merecen más perdón que los adultos por no escapar de las influencias negativas de su medio ambiente" 22 .

En este sentido, en Simmons la Corte decidió que: a) Las personas menores de dieciocho años son diferentes y esta diferencia resulta de un proceso cerebral en formación; b) Puede haber excepciones a la afirmación presente en a), pero nadie puede decir con certeza qué excepciones son esas; y c) Respecto a la pena de muerte, la Corte establece un límite a su imposición a menores de dieciocho años de edad.

\subsection{Schwarzenegger v. Entertainment Merchants Ass'n}

Recientemente, en el caso Schwarzenegger v. Entertainment Merchants Ass'n, la Suprema Corte Norteamericana anuló una ley del estado de California que prohibía la venta o alquiler a menores de videojuegos que hayan sido "catalogados como juegos violentos" (California Civil Code, Section 1746.1)22. La justificación de la ley californiana es la afirmación según la cual los videojuegos violentos pueden causar problemas psicológicos serios en menores de dieciocho años de edad.

El caso se inició el 7 de octubre de 2005, cuando el entonces gobernador del estado de California, Arnold Schwarzenegger ${ }^{23}$, firmó la ley California Civil Code 1746-1746.5 que prohíbe el alquiler o la venta de juegos violentos a menores, estableciendo una sanción de 1.000 dólares por su violación. Según la definición de la referida ley, un juego es violento cuando:

(...) La gama de opciones disponibles para un jugador incluye asesinato, mutilación, desmembramiento o abuso sexual de la imagen de un ser humano, si esos actos están representados en el juego de una manera que realiza cualquiera de las siguientes condiciones:

i) Una persona razonable, teniendo en cuenta el juego en su conjunto, encontraría apelaciones [sic] a un interés desviado o morboso de los menores.

ii) Es claramente ofensivo a las normas vigentes en la comunidad en cuanto a lo apropiado para menores.

22 Steinberg, Laurence y Scott, Elizabeth, Op. Cit., p. 1010.

23 Schwarzenegger v. Entertainment Merchants Association, 08-1448. Disponible en https://www.law. cornell.edu/supct/cert/08-1448 
iii) Hace que el juego, en su conjunto, carezca en forma grave de valor literario, artístico, político o científico para los menores.

iv) Permite al jugador infligir virtualmente graves lesiones a las imágenes de seres humanos o personajes con características sustancialmente humanas de una manera que es especialmente atroz, cruel o depravada en cuanto implica abuso físico o tortura grave a la víctima.

Antes de que la ley produjera sus efectos, Entertainment Merchants Association y Entertainment Software Association, alegando violación del derecho a la libertad de expresión protegido en la Primera Enmienda de la Constitución Americana ${ }^{24}$, invocaron su inconstitucionalidad. El estado de California presentó en sus alegaciones la opinión de especialistas y varias escenas violentas de videojuegos, como Grand Theft Auto Vice City y Duke Nukem 3D, en los cuales las personas son asesinadas de formas distintas y brutales. El tribunal del distrito decidió a favor de los productores y distribuidores de juegos. Después de apelar a la 9a Corte del distrito, esta confirmó la decisión local.

El estado de California pidió entonces que la Suprema Corte debería declarar la constitucionalidad de la ley californiana bajo el estándar legal establecido en Ginsberg v. New York, referido a la prohibición de la exposición de material de contenido sexual. Para reforzar su posición anexó estudios que analizaban el impacto de materiales violentos, incluyendo en ellos videojuegos. Considerando el vasto interés del mercado en el caso, treinta y una opiniones de especialistas fueron presentadas al mismo, financiadas tanto por defensores de la ley como por aquellos que deseaban la declaración de su inconstitucionalidad y, por tanto, la libertad de venta de los videojuegos.

Apoyando la posición del estado de California, tanto la Asociación Americana de Psicología (APA, por sus siglas en inglés, 2005) como la Academia Americana de Pediatría (AAP, por sus siglas en inglés, 2009) emitieron declaraciones formales, afirmando que investigaciones científicas "concluyen que la exposición a videojuegos violentos provoca un aumento en la probabilidad en el comportamiento posterior agresivo en niños y adolescentes (...)" y también que se aprecia cómo "los videojuegos violentos aumentan los pensamientos agresivos, los sentimientos de agresividad, la desensibilización a la violencia física y disminuye el comportamiento prosocial" 25 .

24 Amendment I. "Congress shall make no law respecting an establishment of religion, or prohibiting the free exercise thereof; or abridging the freedom of speech, or of the press; or the right of the people peaceably to assemble, and to petition the government for a redress of grievances".

25 Brief of Amicus Curiae of California State Senator Leland Y. Yee, Ph.D., the California Chapter of the American Academy of Pediatrics, and the California Psychological Association in Support of Petitioners, Brown v. Entm 't Merchs. Ass 'n, 130 S. Ct. 2398 (2010) (n. ${ }^{\circ}$ 08-1448), 2010 WL 2937557. 
Conforme a la decisión de la Suprema Corte, "dado que el acto implica una restricción en el contenido del discurso protegido, esto es inválido a menos que California pueda demostrar que está justificado por un interés gubernamental convincente y está estrechamente demarcado para servir a dicho interés (...)”. Según la conclusión de la Corte, "El estado de California no logró presentar este estándar"26.

Si bien el sistema continental que seguimos en nuestro país para establecer sanciones penales es diferente al que sigue la tradición antes expuesta, dado que utilizamos una estructura dogmática que descansa en la Teoría del Delito, con más de ciento treinta años de desarrollo doctrinario, no es menos cierto que, tal como sucede en el Derecho anglosajón, nuevos avances de las ciencias empíricas poco a poco intentan erosionar las bases del sistema penal, considerando la base del reproche -la idea de libertad del delincuente en el momento del hecho- sería un concepto falaz. Volvería así la clásica discusión entre determinismo y libre albedrío.

Estos incompatibles esquemas han tenido centurias de avances, retrocesos y estancamientos. La conceptualización del hombre como un ser determinado de antemano por su especial fisonomía orgánica, en que la estructura cerebral le predispone a actuar de una forma establecida versus la libertad plena con que gozaría para actuar, eligiendo libremente, por ejemplo, el comportamiento a demérito o el acto socialmente bueno, ha tenido una literatura vasta a lo largo de los años, acuñada por autores de conocida experiencia y tradición científica.

La neurociencia ha entregado un componente nuevo a este antiguo debate que ha sido recibido con intensa cobertura en España, Alemania y Estados Unidos, aportando un esencial dato que a los penalistas puede causarles recelo: en el hombre no hay libertad -nunca la hubo-, elemento fundante tradicional de la culpabilidad, requisito inequívoco para aplicar pena en un Estado Democrático de Derecho, sino más bien, estaríamos determinados en nuestros comportamientos por procesos que no podemos controlar y de los que, por tanto, no se nos debería hacer responsables ${ }^{27}$. Así, el profesor español Bernardo Feijoo Sánchez señala con acierto que, bajo estos parámetros científicos, "no hacemos lo que decidimos, sino que decidimos lo que vamos a hacer de todas maneras" 28 .

26 Brief of Amicus Curiae of California State Senator Leland Y. Yee, Ph.D., the California Chapter of the American Academy of Pediatrics, and the California Psychological Association in Support of Petitioners, Brown v. Entm 't Merchs. Ass ‘n, 130 S. Ct. 2398 (2010) (n. ${ }^{\circ}$ 08-1448), 2010 WL 2937557.

27 Feijóo SÁnchez, Bernardo (2011). “Derecho Penal y Neurociencias. ¿Una relación tormentosa?” en InDret., n. ${ }^{\circ}$ 2, p. 3. Disponible en: http://www.indret.com/pdf/806.pdf [Consulta: 8 de julio de 2016]. 
Estimamos que la mejor manera de presentar esta discusión no puede serlo realizando una refutación con antecedentes fundados en la biología o la anatomía ${ }^{29}$, sino que debemos tratar de dilucidar desde las Ciencias Jurídicas, con sus métodos, doctrinas e historia, si los componentes tradicionales de la culpabilidad pueden servir de auxilio para la supervivencia del concepto, que hoy fundamenta la aplicación de la privación más clara y comunicativamente más brutal de que se vale el Estado para el resguardo del orden social y el restablecimiento normativo: la pena ${ }^{30}$. Por ende, este no es un trabajo de neurociencias, sino que uno de Derecho Penal, que busca reflexionar si la pretendida erosión sufrida es profunda o más bien obedece a una nueva versión del clásico determinismo.

Una reflexión de Hassemer podría ponernos en antecedentes:

En el momento actual, las ciencias naturales gozan de prestigio y tienen poder. Su metodología de la observación domina hoy nuestra cultura cotidiana por completo y sin competencia alguna, y, como es natural, también la obtención de conocimientos en el proceso penal; quien no puede apoyar sus argumentos en la observación, es un loco a nuestros ojos. Mientras que la teología hace tiempo que ha pagado en la cultura occidental su error categórico de pretender poder explicar la génesis de la Tierra -con excepción de algunos relictos creacionistas-, no son pocos entre nosotros los que gustan de la maldad del patólogo de que no ha descubierto alma alguna al abrir el cadáver, por lo que esta, en consecuencia, no existiría ${ }^{31}$.

En opinión de Cancio Meliá ${ }^{32}$, en los últimos años asistimos a un verdadero vendaval en el marco de la discusión filosófico-moral y jurídico-penal, que ha sido generado por los más recientes avances en las investigaciones de las neurociencias. Hace

29 Ilustrativas a este respecto resultan las palabras de HASSEMER: "Vedado me queda un recuento del estado de la biología humana, aunque solo se limitara a lo que genera consecuencias para la concepción jurídico penal de la culpabilidad. Para hacer esto, la orquesta de la biología humana es demasiado polifónica, y mi capacidad para analizar de modo confiable su interpretación, demasiado limitada; no podría asumir la responsabilidad de tal análisis -y mucho menos de un pronósticoTambién está cerrado el camino de reflexionar conjuntamente sobre las hipótesis fundamentales de la biología humana y el Derecho Penal, y concretarlas y desarrollarlas en un procedimiento integrador". Vid., HASSEMER, Winfried. "Neurociencias y culpabilidad en Derecho Penal" en InDret., n. ${ }^{\circ}$ 2, p. 5. Disponible en: http://www.indret.com/pdf/821.pdf [Consulta: 8 de julio de 2016].

30 Entenderemos a la pena no separada con la ejecución de la misma, ya que esta, no obstante el eufemismo de hablar de métodos alternativos a la pena privativa de libertad, por su faz comunicativa es, a fin de cuentas, pena.

31 Hassemer, Winfried, Op. Cit., p. 7.

32 Cancio Meliá, Manuel (2003). "Psicopatía y Derecho Penal: algunas consideraciones introductorias", en Eduardo Demetrio Crespo (dir) y Manuel Maroto Calatayud (coor.). Neurociencias y Derecho Penal. Nuevas perspectivas en el ámbito de la culpabilidad y tratamiento jurídico-penal de la peligrosidad. Madrid: Editorial Edisofer, p. 536. 
poco, Hassemer ${ }^{33}$, recientemente fallecido, describió este debate con la imagen de que desde las neurociencias llegan a los científicos sociales y, más específicamente, a los penalistas, como cantos de sirena que llaman a repensarlo todo: nada más y nada menos que lo que es la base fundamental de todo sistema penal legítimo, el concepto de culpabilidad o, más bien, los fundamentos de ese concepto. En algún momento, en esta discusión uno puede tener la impresión de un déjà vu respecto del intento liderado por la Scuola Positiva a principios del siglo pasado de sustituir las irracionales togas negras por las blancas batas de la ciencia.

Cancio Meliá agrega que, en efecto, es sabido que algunos de los protagonistas de la investigación neurocientífica, y algunos penalistas, piensan que lo que se está descubriendo en estos últimos años acerca del funcionamiento del cerebro, específicamente acerca de cómo tienen lugar los procesos de toma de decisiones, revelan que nuestros puntos de partida fundamentales a la hora de establecer la responsabilidad penal estarían errados. Desde este punto de vista, el vendaval sería el anuncio de una tormenta, de un huracán que trastocará toda nuestra imagen sobre la noción de responsabilidad, y, con ello, modificará para siempre el conjunto del sistema de reacción frente al comportamiento desviado, llevándose consigo el Derecho Penal tal y como lo conocemos. Ello por cuanto, sintética y simplificadamente: la noción jurídico-penal de culpabilidad se asienta en la idea de que al sujeto al que hacemos responsable por sus actos, al que consideramos culpable, le es reprochable lo que ha hecho porque podía actuar de otro modo ${ }^{34}$.

Es memorable, la opción por el Derecho que estableció el Tribunal Supremo Federal Alemán hace décadas, cuando asentó qué sujeto podía decidirse a favor del Derecho y en contra de lo injusto, razón por la que es considerado culpable ${ }^{35}$.

Entonces si es cierto, como afirman los (rectius: algunos) neurocientíficos, que en realidad las decisiones -todas las decisiones- no se toman en aquel estrato del cerebro que llamamos "yo"; es decir, por parte de las estructuras neuronales que configuran la conciencia, sino que la decisión en realidad se acomoda a procesos neuronales no conscientes. En suma, si es cierto que no "hacemos lo que queremos", sino que "queremos lo que hacemos", todo el edificio de la responsabilidad jurídico-penal debería caer por su base y, con él, todo nuestro sistema penal basado en la libertad de elección, el reproche y la culpabilidad, para dar paso a un nuevo modo de tratar el comportamiento desviado, asentado sobre la peligrosidad y su tratamiento, y no sobre la culpabilidad y su castigo. Sin embargo este "optimismo" neurocientífico es precipitado e ingenuo, siendo que la gran mayoría de los

33 HASSEMER, Winfried, op. cit.p. 8

34 Cancio Meliá, Manuel, Op. Cit., p. 536 y ss.

35 BGHSt (Entscheidungen des Bundesgerichtshofs in Strafsachen), Alemania. Decisiones de la Corte Federal en Materia Penal, n. 2 , pp. 194 y ss. 
penalistas estiman que no es necesario remover los cimientos de la culpabilidad, ni del Derecho Penal ${ }^{36}$.

No es necesario, desde esta perspectiva, retomar la discusión sobre el libre albedrío, que parece más propia de la teología natural en la tradición cristiana, porque esta no es la propia de un sistema social como lo es el Derecho penal. Desde la perspectiva del concepto funcional de culpabilidad -desarrollado por Jakobs-, como ha dicho Demetrio Crespo ${ }^{37}$, la fundamentación de la culpabilidad en la prevención general positiva es "inmune" a las dudas sembradas por la neurociencia en torno a la existencia de una libertad humana en sentido enfático-empírico. Desde esta posición se puede decir, ya desde un principio, que la cuestión está mal planteada: el sistema penal es una institución social, por lo que aquello que no llegue a ese plano es sencillamente irrelevante. Si el concepto de culpabilidad viene determinado por las necesidades de la prevención general positiva, es irrelevante que de pronto se descubra que todos los seres humanos están plenamente determinados por procesos neuronales inconscientes u otros factores, ya que ello no podrá modificar las necesidades del control social de ningún modo, al ser la descripción de un fenómeno ubicuo en el entorno. Ya se había señalado que la visión de Jakobs acerca de la culpabilidad lo hacía "impermeable" al objeto de estudio de esta tesis. Incluso para este autor, la discusión sería probablemente intrascendente ${ }^{38}$.

\section{LA PSICOPATÍA COMO TRASTORNO DE LA PERSONALIDAD}

Como es sabido, la psicopatía no pertenece al núcleo duro de enfermedades o anomalías mentales que han sido exhaustivamente investigadas y plenamente descritas por la ciencia médica. Por el contrario, casi toda la investigación estrictamente médico-empírica sobre el fenómeno es muy reciente, está todavía in fieri. Esto se aprecia con claridad en el hecho de que no ha logrado entrar aún en el canon médico del DSM-IV, aunque, según parece, la nueva versión, ahora en elaboración, de este estándar vaya a incorporarla ${ }^{39}$.

De momento, el diagnóstico -y, por lo tanto, la definición- de la psicopatía depende de instrumentos de análisis "externo" de conducta, en particular, de la Psychopathy Checklist/Revised (PCL-R), elaborada por el psicólogo canadiense Hare, mediante la cual se obtiene una puntuación (en principio, sobre veinte ítems) en atención a

36 Cancio Meliá, Manuel, Op. Cit., p. 530.

37 Demetrio Crespo, Eduardo (2011). "Libertad de voluntad, investigación sobre el cerebro y responsabilidad penal. Aproximación a los fundamentos del moderno debate sobre Neurociencias y Derecho Penal", en InDret 2. Disponible en http://www.indret.com/pdf/807.pdf

38 Ibidem.

39 Cancio Meliá, Manuel, Op. Cit., p. 533. 
que concurran en la persona determinadas características de personalidad que se expresan en su conducta.

No se trata de entrar en los pormenores de ese método diagnóstico ni en las características específicas de la psicopatía. A los efectos que aquí interesan, bastará con recordar que la psicopatía consiste en una completa ausencia de empatía, lo que conduce al psicópata a una disposición anormal que puede calificarse de "daltonismo moral": los psicópatas presentan una completa ausencia de frenos inhibitorios respecto de la realización de comportamientos socialmente desvalorados ${ }^{40}$.

De acuerdo con la definición de la psicopatía que parece ser dominante, estas características, en primer lugar, se presentan en un continuo, es decir que desde la "normalidad" hasta la psicopatía más grave hay una escala gradual; en segundo lugar, no existe hasta el momento tratamiento alguno para la psicopatía -afirmándose, incluso, que intentarlo puede tener efectos negativos- como se ha visto con base en la experiencia penitenciaria; y en tercer lugar, no están claras las causas de esta disposición, siendo la aproximación mayoritaria multifactorial, en la que concurrirían tanto elementos presentes desde el nacimiento como influencias derivadas de la historia vital del individuo, del entorno (sosteniéndose por parte de algunos -sin que esto sea generalmente aceptado- que habría, en correspondencia, psicópatas primarios y secundarios, siguiendo la clasificación de Robert D. Hare).

Según parece, la psicopatía es una constante antropológica. En todas las épocas y en todas las culturas un porcentaje estable de la población puede ser considerado psicópata, en torno a un 0,5 a 1,5\% de los varones, aunque se piensa que es en realidad un $2 \%$ porque, de acuerdo con un sector de los autores -como dicen destacados neurocientíficos-, por razones que "siguen siendo un misterio" 41 , es un fenómeno casi exclusivamente masculino. Estos sujetos presentan una tendencia a cometer infracciones criminales que cabe considerar muy superior al resto de la población: las estimaciones que circulan afirman que de un $15 \%$ a un $25 \%$ de la población reclusa está constituida por autores psicópatas ${ }^{42}$.

Sin embargo, el statu quo de la investigación científica respecto de la psicopatía está cambiando de una manera radical desde hace algunos (pocos) años. El protagonista de esta evolución es, junto con otros métodos de neuroimagen, el procedimiento de escáner cerebral llamado fMRI que tanta relevancia tiene, en general, en los nuevos avances neurocientíficos. Esta técnica mide -y representa gráficamente en una imagen del cerebro- la actividad hemodinámica cerebral. Por lo tanto, no se trata de una

\section{Ibidem.}

41 Kiehl, Kent A. y Buckholtz, Joshua W. (2010). "Inside the Mind of a Psychopath", en Scientific American, sept-oct. 2010, pp. 22 y ss.

42 Cancio Meliá, Manuel, Op. Cit., p. 533. 
"fotografía" de la actividad neuronal en sí misma, sino de una de sus consecuencias, esto es, una mayor irrigación sanguínea que delata la actividad neuronal. Lo que se hace para medirla es subdividir al cerebro en unos ciento treinta mil cubos de unos tres milímetros de dimensión de lado -los vóxeles- y se mide para cada uno de ellos dos veces la señal BOLD (Blood Oxygen Level Determination): una vez en estado de reposo y otra, cuando se le demanda a la persona sometida al ensayo que realice una determinada tarea (como puede ser contemplar una imagen). La señal será más intensa cuanto mayor sea el nivel de oxígeno demandado, que crece cuanto mayor es la actividad neuronal. La computadora calcula para cada uno de los vóxeles por separado si existe una diferencia significativa de irrigación $-y$, en consecuencia, de actividad neuronal- en la situación de reposo o en la tarea hecha en el ensayo. De ahí se obtiene una neuroimagen tridimensional, una vez coloreadas las diferencias, de la que cabe deducir muchos elementos de la morfología funcional del cerebro examinado ${ }^{43}$.

Así se abre una puerta, por primera vez en la historia de la humanidad, que resulta decisiva también para el estudio de la psicopatía: en lugar de aproximarse al fenómeno desde afuera, esto es, desde el comportamiento de quien padece la afección, o de sus propias manifestaciones acerca de determinadas características de su personalidad y de su conducta, se puede observar directamente el funcionamiento del cerebro, identificando así diferencias anatómico-funcionales entre psicópatas y no psicópatas. Estos estudios, en rapidísimo progreso en la actualidad, han generado, en lo esencial, dos hipótesis: por un lado, varios autores apuntan a diferencias morfológicas en el sistema de respuesta emocional (admígdala y sistema paralímbico) ${ }^{44}$; y por otro, a diferencias en el ciclo de ansiedad/atención ${ }^{45}$. En todo caso, son innegables los paralelismos entre sujetos psicópatas y personas que han sufrido lesiones en el córtex ventromedial prefrontal ${ }^{46}$.

Ahora bien, y esta es una de las más importantes cautelas, el principal if: En la actualidad, esta técnica -igual que otras similares-está aún lejos de proveer conclusiones claras, debido a que se encuentra aún en una fase inicial desde el punto de vista metodológico, lo que no dejan de reconocer sus más entusiastas promotores ${ }^{47}$. En primer lugar, por mucho que a un lego le pueda parecer que tres milímetros de lado,

43 Ibidem.

44 Anderson, Nathalien E. y Kiehl, Kent A. (2012). "The psychopath magnetized: insights from brain imaging", en Trends in Cognitive Sciences, n. ${ }^{\circ} 16$, pp. 52 y ss.

45 Glass, Samantha J. y Newman, Joseph P. (2009). "Emotion Processing in the Criminal Psychopath: The Role of Attention in Emotion-Facilitated Memory", en Journal of Abnormal Psychology, n. ${ }^{\circ}$ 118 , pp. 229 y ss.

46 Koenigs, Michael; Kruepke, Michael y Newman, Joseph P. (2010). "Economic decision-making in psychopathy: A comparison with ventromedial prefrontal lesion patients" en Neuropsychologia, n. ${ }^{\circ} 48$, pp. 2198 y ss.

47 Anderson, Nathalien E. y Kiehl, Kent A., Op. Cit., p. 58. 
y ciento treinta mil vóxeles, es mucha resolución, en realidad es una red muy, muy gruesa: cada vóxel contiene entre trescientos mil y tres millones de neuronas, cien kilómetros de líneas neuronales y veintisiete mil millones de sinapsis. En segundo lugar, es esencial la decisión del director del ensayo a la hora de fijar el umbral de relevancia en la actividad hemodinámica que estime relevante. En este sentido, es famoso el artículo, firmado por un grupo de neuropsicólogos liderado por Craig M. Bennett ${ }^{48}$, que da cuenta de un experimento hecho con ayuda de la técnica fMRI. En este experimento, se mostraron al individuo sometido al ensayo una serie de fotografías de personas exteriorizando diversos estados emocionales, para averiguar la respuesta neuronal del sujeto. Este mostró, como en otros experimentos de este tipo, significativas diferencias en la reacción neuronal frente a unas y otras imágenes. Cosa bastante sorprendente, pues se trataba de un salmón muerto. Se observa, pues, que dependiendo de la disposición del ensayo en cuanto a la relevancia de los parámetros de medición, se puede obtener prácticamente siempre una respuesta ${ }^{49}$. Aunque lo anterior revela un fallo del método en forma casi hilarante, y se muestran de manera muy gráfica la inseguridad del mismo, hay neurocientíficos que están específicamente convencidos de que existe la posibilidad de retratar las bases neurofisiológicas de la psicopatía. Actualmente, el intento más ambicioso es el que ha venido desarrollando el neurocientífico Kiehl en el estado de Nuevo México. Viajando de centro penitenciario en centro penitenciario, se somete a examen mediante fMRI - usando un equipo móvil ubicado en un camión- a un grupo importante de presos diagnosticados como psicópatas por métodos tradicionales, para así reunir por primera vez datos significativo, con una base de datos de alrededor de mil individuos que permita avanzar en la identificación de las bases neurofisiológicas de la psicopatía, y, con ello, establecer un método de diagnóstico más seguro -y más visible para su procesamiento forense- que el (ahora ya) tradicional, basado en la PCL/R de Hare ${ }^{50}$.

Supongamos hipotéticamente que en el futuro el citado método sea validado y que por tanto es fiable. Y recordemos cuáles son los elementos nucleares de la psicopatía: un déficit en la capacidad de empatía y, como consecuencia de ello, una incapacidad innata para el razonamiento moral, para reconocer emocionalmente la diferencia entre la conducta correcta y la errónea. No se trata de que los sujetos en cuestión no puedan comprender racionalmente qué está prohibido y qué no, o que no puedan controlar sus impulsos. Se trata de que lo uno y lo otro les es, por principio y radicalmente, indiferente en el plano emocional, porque carecen de las estructuras

48 Bennet, Craig M. et al. (2010). "Neural Correlates of Interspecies Perspective Taking in the PostMortem Atlantic Salmon: An Argument for Proper Multiple Comparisons Correction”, en Journal for Serendipitous and Unexpected Results, n. ${ }^{\circ}$ 1(1), pp. 1-5.

49

Cancio Meliá, Manuel, Op. Cit., p. 535.

50 Cancio Meliá, Manuel, Op. Cit., p. 537. 
neuronales normales que tiene la abrumadora mayoría de los integrantes de cualquier grupo humano ${ }^{51}$.

En principio, podría pensarse que es un supuesto en el que la culpabilidad es expresión del carácter del sujeto, una "emanación de su personalidad", en la clásica formulación de Dohna. Es el modo de ser del psicópata el que lo hace no tener en cuenta a los demás, no considerar los intereses ajenos y, por lo tanto, delinquir por una nimiedad con tal de que su interés egoísta quede satisfecho. Sin embargo, y con las cautelas antes referidas acerca de los necesarios niveles de certeza en el diagnóstico que aún deben alcanzarse con las nuevas tecnologías es necesario al menos plantear otra solución. Conviene recordar las bases de la atribución de responsabilidad personal, a partir de la construcción social de la culpabilidad y de acuerdo con la concepción funcional de culpabilidad (sin que eso implique caer en el funcionalismo de Jakobs). De acuerdo con este punto de vista, la culpabilidad es una magnitud que deriva de las necesidades de la prevención general positiva, es decir, la culpabilidad significa que la explicación de la infracción de la norma ocurrida es asignada al infractor, por ausencia de una explicación alternativa. La consecuencia es la imposición de una pena al infractor como mecanismo de estabilización contrafáctica de la norma ${ }^{52}$.

Además, el momento presente se caracteriza por una progresiva dosis de inseguridad jurídica, acrecentada por los trepidantes cambios socio-económicos y políticos, así como por la irrupción de los avances tecnológicos. Ante este camino incierto iniciado por un Derecho Penal en expansión, administrativizado y utilizado disparatadamente -ahora más que nunca- con el pragmatismo de un arma política ${ }^{53}$, se hace preciso insistir en la idea de elaborar un Derecho Penal próximo al método científico en sentido estricto. Precisamente, en el ámbito de la imputabilidad debe reivindicarse una íntima relación entre el conocimiento psiquiátrico, genético y la argumentación penal, de tal modo que permita estructurar sobre bases científicas fiables un discurso racional y multidisciplinar, tratando de recuperar la mutua confianza que debe gobernar la coordinación médica y jurídica en este campo ${ }^{54}$, a efectos de esclarecer

\section{Ibidem.}

52 Cancio Meliá, Manuel, Op. Cit., p. 537.

53 Prittwitz, Cornelius (2000). "El Derecho Penal alemán, ¿fragmentario?, ¿subsidiario?, ¿última ratio?”, en AA.VV. La insostenible situación del Derecho penal (trad. Profesores del Área de Derecho Penal de la Facultad de Derecho de la Universidad Pompeu Fabra). Granada: Editorial Comares, p. 428.

54 Como indica la profesora Huerta TociLdo, SusAna (1997). "La teoría jurídica de la inimputabilidad se convierte en la puerta de entrada en el campo del Derecho Penal de la moderna investigación científica acerca de la personalidad humana", cfr. "Piquiatría y nuevo Código Penal”, (ponencia inédita presentada al Seminario de Psquiatría Forense, celebrado en Eurofórum de El Escorial, febrero de 1997). 
con mayor certidumbre los factores desencadenantes del acto y las capacidades del sujeto de comprender lo ilícito de su actuación ${ }^{55}$.

Naturalmente, no cabe esperar de modo automático que este necesario acercamiento entre Psiquiatría, Genética y Derecho resuelva mágicamente todos los problemas que la praxis clínica y criminal presenta en la realidad diaria de cara a delimitar la frontera entre la plena responsabilidad penal y las hipótesis encuadrables en el plano de la inimputabilidad ${ }^{56}$.

A título meramente ejemplificativo, podemos adelantar algunas inseguridades no fácilmente remediables en el ámbito penal sustantivo y en el proceso penal.

En primer lugar, la indagación de un estado psicológico resulta ciertamente complicada porque las dimensiones anímicas no son fácilmente delimitables ni susceptibles de medición matemática. No hay fórmulas irrefutables que puedan certificar el funcionamiento ni lo que discurre por el cerebro de cualquier ser humano, sano o enfermo ${ }^{57}$; situación que se complica aún más ante las profundas discrepancias existentes entre las distintas corrientes doctrinales en el ámbito de la psiquiatría a la hora de diagnosticar un caso o emitir un determinado informe pericial. No es de extrañar entonces que todas las conclusiones divergentes que confluyen en el análisis de la conducta de un sujeto contribuyen, en cierto modo, a mermar credibilidad entre los profanos o relativizar el incuestionable carácter científico de los resultados alcanzados ${ }^{58}$. Y, si además interviene un Tribunal con Jurados, cuyos miembros no se encuentran familiarizados con las sutiles disquisiciones jurídicas ni con la ininteligible terminología médica o bioética, a la hora de decidir pueden sentirse más influidos

55 Iglesias Río, Miguel Ángel (2003). "La eximente de ‘anomalía o alteración psíquica'. Una problemática abierta hacia el futuro científico”, en $A D P C P$, Vol. LVI, p. 155.

56 De hecho, en algunos momentos, la función de la psiquiatría en general y sus métodos de tratamiento forense han sido puestos en cuestión no solo por parte de los juristas sino también por la propia ciencia médico-legal, llegándose a generalizar una sensación de cierto pesimismo y desconfianza ante los resultados alcanzados y a discutir incluso la delimitación del ámbito competencial entre Psiquiatría y Derecho. Más aún, algunas corrientes han propuesto renunciar en muchos casos a los diagnósticos psiquiátricos y concentrar los esfuerzos en terapias de orden social. No obstante, el desarrollo de la psiquiatría ha evidenciado que el rechazo al diagnóstico es un camino erróneo y que una clasificación lo más precisa posible de las anomalías psíquicas es una condición indispensable para la solución de los problemas del sujeto. Vid. IgLesias Río, Miguel Ángel, op. cit. pp. 155-156.

57 En parte, debido a la crisis que afecta al propio concepto de "enfermedad" y sus límites fronterizos con la "normalidad", al menos en sentido técnico, especialmente si se acepta, como se dice, que en el ochenta por ciento de la población se puede detectar algún grado de enfermedad mental (aunque, evidentemente, no sea penalmente relevante). Vid. IGLESIAS Río, MiguEL ÁnGEL, op. cit. p. 156, nota a pie de p. $\mathrm{n}^{\circ} 17$.

58 Parece inevitable que los expertos incorporen en sus dictámenes juicios de valor personales o las propias preconcepciones culturales, aun cuando ello desestabilice de algún modo la objetividad de su actuación profesional. 
por las imágenes preconcebidas en la literatura o en el cine que por el contenido de los dictámenes técnicos ${ }^{59}$.

En segundo lugar, el análisis de los distintos elementos del delito, también por supuesto el juicio sobre la capacidad de culpabilidad del sujeto, ha de referirse retroactivamente al instante puntual y concreto en que actuó u omitió la acción debida, no al momento del resultado ni tampoco al momento presente en el que se tramita el procedimiento penal ${ }^{60}$. Esto añade una dificultad más si cabe, de naturaleza probatoria en sede procesal al tema que nos ocupa, porque todo peritaje psiquiátrico debe proceder a una reconstrucción ex post facto de aquel originario estado mental o psicológico del sujeto -que, sin embargo, no es susceptible de una reproducción experimental idéntica- para decidir si, al momento del hecho, estaba en condiciones de responder a la norma. No es extraño que tal exploración sobre el presunto autor del delito se realice semanas, meses o incluso años después de la comisión del hecho delictivo ${ }^{61}$. Cuando esto es así, los especialistas en medicina legal reconocen que dicha exploración puede arrojar unos datos indicativos de que la patología o los factores codeterminantes del hecho hayan experimentado una aminoración considerable o, sencillamente, que por tratarse de un supuesto trastorno mental transitorio no se detecta o, excepcionalmente, no ha quedado rastro de déficit morboso alguno con base patológica endógena ni exógena ${ }^{62}$ que pudiera singularizar su repercusión en las capacidades del sujeto ${ }^{63}$.

Desde otra perspectiva, a estos problemas hay que sumar los que pudieran derivarse de una exploración llevada a cabo cuando el sujeto se encuentra sometido a tratamiento farmacológico o mediatizado por el consumo de drogas tóxicas, pues

59 García BlázQuez, Manuel (1997). Análisis médico-legal de la imputabilidad en el Código penal de 1995. (Un análisis médico-legal de los arts. 20.1 y 20.2), Granada: Editorial Comares, pp. 30-31.

60 TORÍo LóPEZ, ÁNGEL (1981). "La capacidad limitada de autodeterminación en la reforma del sistema penal", en AA.VV. Jornadas de estudio de la deficiencia mental en la región castellano-leonesa, Valladolid,pp. 15 y ss.; del mismo "Las fórmulas legislativas sobre la enfermedad mental. Discusión del concepto de enajenación”, en Santiago Mir Puig, Juan CóRdoba Roda y Gonzalo Quinetero Olivares (coords.) (1983). Estudios jurídicos en honor del Prof. O. Pérez Vitoria. Barcelona: Editorial Bosch, pp. 967 y ss.

61 Así ha sucedido en una serie de casos muy conocidos, entre los que podemos recordar el del asesino de los naipes en Madrid, las muertes de las jóvenes de Mijas y Coín o de un matrimonio en Talavera, acaecidas hasta diez años antes de la detención de los sospechosos.

62 En los supuestos de trastorno mental transitorio, aunque generalmente descansan sobre una "base constitucional morbosa o patológica", no es exigible su comprobación para apreciar la eximente, como estima la STS 15-4-98, al determinar que "en persona sin tara alguna posible la aparición indicada de indicada perturbación fugaz, una reacción vivencial anormal, tan enérgica y avasalladora para la mente del sujeto que la priva de toda capacidad de raciocinio, eliminado y anulando el choque psíquico originado por un agente exterior, cualquiera que sea su naturaleza”.

63 Iglesias Río, Miguel Ángel, Op. Cit., p. 158. 
los resultados obtenidos en estas condiciones estarían viciados y tendrían que equipararse a la práctica de una "prueba prohibida" análoga al caso del narcoanálisis ${ }^{64}$.

En tercer lugar, la determinación concreta del juicio de imputabilidad se complica todavía más desde el momento en que debe ser el resultado de un proceso individualizado, sin que pueda acudirse al criterio abstracto del hombre medio o al parámetro impersonal de un hipotético sujeto racional ${ }^{65}$. Incluso, se ha demostrado desde el punto de vista médico-legal que las disfunciones que presentan algunas anomalías, como las neurosis obsesivas o las alteraciones pasionales, se manifiestan o inciden solo en determinados -no en todos-ámbitos conductuales exógenos que han podido influir en la conducta o morfología del acto ${ }^{66}$.

\section{CONCLUSIÓN}

Para el hallazgo de una explicación completa del comportamiento de individuos con trastornos de la personalidad y psicópatas debe tenerse en cuenta, en el ámbito de la imputabilidad, una íntima relación entre el conocimiento psiquiátrico, genético y la argumentación penal, de tal modo que permita estructurar sobre bases científicas fiables un discurso racional y multidisciplinar, tratando de recuperar la mutua confianza que debe gobernar la coordinación médica y jurídica en este campo, a efectos de esclarecer con mayor certidumbre los factores desencadenantes del acto y las capacidades del sujeto de comprender lo ilícito de su actuación.

Una observación más amplia y abarcadora del fenómeno de la conducta permite afirmar que, además del cerebro, debe considerarse otro grupo de elementos como los mencionados precedentemente. Cada uno de ellos, evaluados en su conjunto, constituyen la respuesta integradora acerca de los factores gravitantes para una determinada manifestación de voluntad, conclusión que, obviamente, nos lleva a un puerto completamente diferente respecto de la problemática referida a la confluencia entre "derecho y neurociencias".

Si a todo esto le trasladamos el interrogante central que formulamos anteriormente en cuanto a si ¿era o fue él o su cerebro?, la respuesta en este caso no será "son uno y el mismo", sino que se podrá decir que "es uno y su circunstancia", que incluye y comprende toda esta otra serie de elementos concurrentes que, en forma conjunta y al unísono, justifican el comportamiento humano como manifestación de toda la persona sin identificarlo exclusivamente con las funciones encefálicas.

64 García BlázQuez, Manuel, Op. Cit., pp. 24 y ss., esp. 28 y ss. Naturalmente, a no ser que se tratase de una hipótesis encuadrable en el art. 20.2 CP. 
Liberados de esta suerte de determinismo cerebral, donde todo encuentra su razón de ser a través del condicionamiento inferido de sus propias funciones, la neurociencia busca encontrar sus espacios de autonomía dentro del terreno más amplio como el que constituyen las ciencias normativas, aportando su cuota de certidumbre en lo que respecta a los elementos de prueba, como así igualmente, y desde una visión filosófica, sobre los conceptos de Justicia, Moral y Libertad.

Desde esta perspectiva, el "dualismo" coopera indudablemente aportando diagnósticos certeros o juicios científicos con validez universal que permiten, frente a ciertas situaciones, una mejor comprensión de las conductas, pero siempre fuera de esa suerte de subsunción absoluta del cerebro respecto de todo lo que conforma en su integridad el ser humano, tanto en aspectos estrictamente discursivos o racionales, como así en lo referido a sentimientos, emociones, estructuras culturales, genéticas, etcétera.

A la luz de lo relacionado precedentemente, cabe concluir que la actividad neuronal por sí misma no es suficiente para encontrar el fundamento y desarrollo del comportamiento de los hombres, porque el conocer o tener conciencia de las cosas que nos ocurren o rodean no es solo tener cerebro a través de un particular estado físico o anatómico, sino que debe integrarse con las demás habilidades sicológicas y categorías mentales que lo integran y completan, según lo ha desarrollado esta teoría con todo cuidado y prolijidad.

En definitiva compartimos el juicio de Pardo y Patterson cuando plantean la disyuntiva acerca de dónde se encuentra situada la mente, si en el alma cartesiana o, por el contrario, en el cerebro, y nos proponen como mejor respuesta la aseveración de que la conducta humana constituye el "criterio del conocimiento" y no un "estado cerebral" 67 .

Nuestras conclusiones referidas a la problemática de la confluencia entre Derecho y Neurociencia, consisten en apartarnos de toda posición unilateral o sesgada del fenómeno, porque entendemos que estos avances experimentados por la medicina respecto del estudio del cerebro se transformarán en una ciencia auxiliar imprescindible en el funcionamiento de la justicia, pues aportarán certidumbre y certeza en los mecanismos de comprobación o descubrimiento de la verdad, como así in-

67 Pardo, Michael y Patterson, Dennis (2011). "Fundamentos filosóficos del derecho y la neurociencia", en InDret, 2, nota 9, pp. 8 y 17, http://www.indret.com/pdf/819.pdf Sostienen los autores de la nota que constituye una falacia mereológica (falacia relativa a la relación lógica entre las partes y el todo) en atribuir la capacidad o la función a una parte, lo que solo es atribuible correctamente al conjunto del cual aquella no es más que eso, una parte. Con referencia a autores como el filósofo DANIEL DENNET, el neurocientífico MAXWELl BENNET y el filósofo PETER HACKER responden que "en el sentido que el ser humano posee información el cerebro no posee nada". Continúan desarrollando este pensamiento afirmando: "Conocer no es estar en un estado particular. El conocer es una capacidad, por ejemplo, de responder a la pregunta correctamente. La medida de veracidad de su respuesta no se encuentra en el estado neuronal de su cerebro". 
cluso respecto de sus resultados o veredictos, pero seguimos convencidos de que la libertad y el libre albedrío del hombre -y de todo hombre- constituye el elemento imprescindible para construir el concepto de responsabilidad, sin la cual resulta difícil comprender la esencia y razón de ser de las ciencias normativas. En definitiva, auguramos una convivencia cada vez más estrecha, quizá con un incremento proporcional al estado de avance de sus investigaciones y estudios, pero todo ello sin que destruya el basamento moral ${ }^{68}$ de la libertad de las personas.

\section{BIBLIOGRAFÍA}

Anderson, N. E. y KIEHL, K.A. (2012). “The psychopath magnetized: insights from brain imaging", en Trends in Cognitive Sciences, n. ${ }^{\circ}$ 16, pp. 52-60.

Bennet, C. M., et al. (2010). "Neural Correlates of Interspecies Perspective Taking in the Post-Mortem Atlantic Salmon: An Argument for Proper Multiple Comparisons Correction", en Journal for Serendipitous and Unexpected Results, n. ${ }^{\circ}$ (1), pp. 1-5.

Cancio Melí́, M. (2013). "Psicopatía y Derecho Penal: algunas consideraciones introductorias", en Neurociencias y Derecho Penal. Nuevas perspectivas en el ámbito de la culpabilidad y tratamiento jurídico-penal de la peligrosidad. Madrid: Ed. Edisofer.

Capó, M.; Nadal, M.; Ramos, C.; Fernández, A.; Cela Conde, C. J. (2006). “Neuroética, derecho y neurociencia", en Ludus Vitalis, vol. XIV, n. ${ }^{\circ} 25,2006$, pp. 163 y ss.

Demetrio Crespo, E. (2011). “Libertad de voluntad, investigación sobre el cerebro y responsabilidad penal. Aproximación a los fundamentos del moderno debate sobre Neurociencias y Derecho Penal", en InDret, n. ${ }^{\circ}$, pp. 1-38.

ECHARTE, L., "Hacia una nueva filosofía de la neuroética” http://www.enciclopediadebioetica.com/index.php/todas-las-voces/192-neuroetica-hacia-una-nuevafilosofia-de-la-neurociencia

68 Echarte, L. "Hacia una nueva filosofía de la neuroética". En este importante trabajo se define la neuroética como el conjunto de estudios que ponen en relación la neurociencia con las ciencias sociales. El autor cita, a su vez, el pensamiento de HARPER, director de la prestigiosa Dana Foundation, emitida durante las sesiones del Congreso de San Francisco de 2002, cuando refiriéndose a este problema, expresó: "Puede llamársela como se quiera (...) pero el tren de la neuroética ya ha salido de la Estación". Cierra estas reflexiones, con el pensamiento de BANGA, J., director de Heatlh Sciences of Clinical Ethics, de la Emory University, en el sentido de que "la contribución de las ciencias sobre el cerebro a nuestro conocimiento de la naturaleza del razonamiento moral y de la conducta moral". En definitiva, subraya el autor acerca de la necesidad de una toma de conciencia sobre cómo puede llegar a cambiar la neurociencia nuestra comprensión del fenómeno humano y qué efectos se derivan de dicho cambio. 
Ellis, H. D. y Lewis, M. B. (2001). "Capgrass delusion: A window on face recognition”, en Trends in Cognitive Sciences, n. ${ }^{\circ}$ 5, pp. 4.

FEIJóo SÁnchez, B. (2011). “Derecho Penal y Neurociencias. ¿Una relación tormentosa?", en InDret., n. ${ }^{\circ}$, pp. 1-57.

García Blázquez, M. (1997). Análisis médico-legal de la imputabilidad en el Código penal de 1995. (Un análisis médico-legal de los arts. 20.1 y 20.2). Granada: Ed. Comares.

GARZÓn VALDÉs, E. (enero, 2011). “Cerebro y responsabilidad penal”, en Seminario de Filosofía del Derecho. Barcelona: Universidad Pompeu Fabra.

Hassemer, W. (2011). "Neurociencias y culpabilidad en Derecho Penal", en InDret., n. ${ }^{\circ}$, p. 5. Disponible en: http://www.indret.com/pdf/821.pdf [Consulta: 8 de julio de 2016], pp. 1-14.

Huerta Tocildo, S. (1997). "Piquiatría y nuevo Código Penal”, (ponencia inédita presentada al Seminario de Psiquiatría Forense, celebrado en Eurofórum de El Escorial, febrero de 1997).

IgLesias Río, M. A. (2003). “La eximente de ‘anomalía o alteración psíquica' . Una problemática abierta hacia el futuro científico”, en ADPCP, Vol. LVI, pp. 151-173.

Kiehl, K. A. y Buckholtz, J. W. (sep-oct., 2010). "Inside the Mind of a Psychopath", en Scientific American, pp. 22-29.

Koenigs, M.; Kruepke, M. y Newman, J. P. (2010). "Economic decision-making in psychopathy: A comparison with ventromedial prefrontal lesion patients", en $\mathrm{Neu}$ ropsychologia n. $^{\circ} 48$, pp. 2198-2204.

Pardo, M. S. y Patterson, D. (abril, 2011). "Fundamentos filosóficos del derecho y la neurociencia”, en InDret. Barcelona, pp.1-51. Disponible en http://www.indret. com/pdf/819.pdf,

PritTwitz, C. (2000). “El Derecho Penal alemán, ¿fragmentario?, ¿subsidiario?, ¿ultima ratio?”, en La insostenible situación del Derecho penal (trad. Profesores del Área de Derecho Penal de la Facultad de Derecho de la Universidad Pompeu Fabra).

Schiffer, B.; Peschel, T.; Gizewski, T.; Forsting, E.; Leygraf, M.; SchedlowsKI, N.; Krueger, M.; TillmanN, H. C. (2007). "Structural brain abnormalities in the frontostrital system and cerebellum in pedophilia", en Journal of Psychiatric Research, 41(9), pp. 753-762. 
SteinberG, L. y Scott, E. (2003). “Less Guilty by Reason of Adolescence: Developmental Immaturity, Diminished Responsibility, and the Juvenile Death Penalty, en Am. Psychologist, Vol. 58, n. ${ }^{\circ}$ 12, pp. 1009-1018.

SwERDLOw, R. H. (2003). "Right orbitofrontal tumor with pedophilia symptom and constructional apraxia sign”, en Archives of Neurology, n. ${ }^{\circ} 60$, pp. 437-440.

Torío López, A. (1981). "La capacidad limitada de autodeterminación en la reforma del sistema penal”, en Jornadas de estudio de la deficiencia mental en la región castellano-leonesa. Valladolid, pp. 15 y ss.

Torío López, A. (1983). "Las fórmulas legislativas sobre la enfermedad mental. Discusión del concepto de enajenación", en Estudios jurídicos en honor del Prof. O. Pérez Vitoria. Barcelona: Ed. Bosch.

Tost, H.; Vollmert, C.; Brassen, S.; Schmitt, A.; Dressing, H.; Braus, D. F. (2004) "Pedophilia: Neuropsychological evidence encouraging a brain network perspective", en Medical Hypothesis, 63(3). 